\title{
Comparison of Dynamic Changes of Endogenous Plant Hormones and Hormone-Related Gene Expression between Near Isogenic Lines with Normal Spike and Branched Spike Wheat
}

\author{
Li Qianqian ${ }^{1}$, Jiang Xiaoli ${ }^{1}$, He Fengli ${ }^{1}$, Zhang Weidong ${ }^{1,2} \&$ Gao Qingrong ${ }^{1,2}$ \\ ${ }^{1}$ Agronomy College, Shandong Agricultural University, Taian, Shandong, China \\ ${ }^{2}$ State Key Laboratory of Crop Biology, Taian, Shandong, China \\ Correspondence: Zhang Weidong, Agronomy College, Shandong Agricultural University, Taian 271018, \\ Shandong, China. E-mail: zhangwd@sdau.edu.cn
}

Received: March 25, 2015 Accepted: May 7, 2015 Online Published: June 15, 2015

doi:10.5539/jas.v7n7p203 URL: http://dx.doi.org/10.5539/jas.v7n7p203

\begin{abstract}
Branched spike wheat is a hexaploid wheat with branched rachis on its main rachis, and branched rachises in the shoot apex occur and develop just after the two ridges stage. In this study, dynamic changes of four endogenous plant hormones [indole-3-acetic acid (IAA), gibberellic acid (GA), abscisic acid (ABA) and zeatin riboside (ZR)] and the expression of a hormone-related gene were measured among wheat lines with different genotypes and spike morphologies. It is a basis for further exploring the developmental mechanisms of branched spike and for breeding new wheat lines with more spikelets and grains. A group of near isogenic lines (NILs), including one branched spike line, and three normal spike type lines was sampled at four time points from the end of two ridges stage to the floret differentiation stage. The endogenous hormones in young shoots, young leaves and tillering nodes in these lines were measured and the expressions of TaIAR3, encoding IAA amide hydrolase which involvs in the IAA synthesis was detected. The results showed that the contents of IAA exhibited a significant different pattern in branched spike line from those in normal spike lines, while the contents of GA, ABA and ZR showed similar change patterns. The expressions of TaIAR3 were also significantly different between branched spike line and normal spike lines. Both the IAA content and TaIAR3 expression in branched spike wheat were much higher than those in the normal spike lines. These results suggest that quantitative changes in auxin may correspond to different spike morphology. Higher IAA content and TaIAR3 expression might be benefical for promoting the formation and elongation of branched rachis in branched spike wheat line.
\end{abstract}

Keywords: Triticcum aestivum, branched spike wheat, near isogenic lines (NILs), endogenous hormones, auxin, TaIAR3

\section{Introduction}

Branched spike wheat is a special hexoploid wheat germplasm which has branches (branched rachises) on its main rachis and bears an overabundance of spikelets and grains on a spike. The grain number in a branched spike can reach 70-130 while that in a single normal spike generally is 35-70. Branched spike wheat has great application potentials in wheat production areas with high speed of grain filling or long term of grain filling period.

The branching characters of these spikes were incorporated into $T$. aestivum from branching forms of $T$. turgidum by distant hybridization (Koric, 1980; Dencic, 1988; Huang et al., 1988). A number of studies have been conducted on the branched spike wheat in genetic characters and field performances. The inheritance of the spike branch $(s b)$ in common wheat was found to be controlled by two recessive genes in cross experiments between normal spike and branched spike lines (Koric, 1980). This supernumerary spikelet character in this type of spike was also affected by light, temperature, nutrients and environmental conditions (Koric, 1975; Peanell, 1983), and environmental factors played a minor effect on the character expression during spike differentiation stage at the same eco-region (Sun et al., 2000).

Shoot and inflorescence branching are the key determinants of plant architecture above ground. Shoot branching is usually associated with hormonal changes. Auxin has long been known to contribute to branching, although the mechanistic basis of its function remains somewhat ambiguous (Waldie et al., 2010; Domagalska \& Leyser, 
2011). Apical dominance of auxin in a plant generally inhibits germination and growth of lateral buds, but auxin also take part in the occurrence and development of axillary meristems (Foo et al., 2005; Beveridge, 2006). Auxin influence the formation and growth of lateral branches by regulating the expression of MAX/RMS gene in Arabidopsis (Leyser, 2003). Cytokinins have been considered as candidates for an auxin second messenger, as they have the potential to promote bud outgrowth and cytokinin abundance in or near the bud correlates with bud fate (Emery et al., 1998; Tanaka et al., 2006). GA promotes branching growth, and the reduction of GA leads to new branches to stop growth in apple (Hooijdonk et al., 2011). Strigolactone and its derivatives are a new kind of plant hormone which generally inhibits shoot branching formation (Gomez-Roldan et al., 2008, Umehara et al., 2008). Other data provide evidence that a strigolactone-derived hormone associated with the pea (Pisum sativum) RAMOSUS pathway and the Arabidopsis MORE AXILLARY GROWTH pathway could be an auxin second messenger (Brewer et al., 2009).

However, there were relatively few studies on the effects of hormones on the inflorescence branches due to the lack of suitable research materials, and there were no reports on the dynamic changes of endogenous hormones in a branched spike development process in wheat. In this study, a set of near isogenic lines with two different spike types was used to investigate the changes of endogenous hormones and the expression of a key gene related with IAA synthesis during the branched spike developmental process. This study might lay foundation for further exploring relationships between the occurrence and development of branched spike and the contents of endogenous hormones, and establishing strategies for breeding new wheat varieties with branched spike and more grains per inflorescence.

\section{Materials and Methods}

\subsection{Experimental Materials}

A set of near isogenic wheat lines with different genotypes and spike morphologies was used in this study. The near isogenic lines (NILs) were obtained from backcross progenies of Fen33, a released branched spike variety in HuangHuan wheat zone in China, and Taishan 008, a normal spike line as the recurrent parent (Zhang et al., 2012). This set of NILs included a branched spike line, double recessive line DR ( $s b 1 s b 1 s b 2 s b 2)$, and three normal spike lines, which are two single recessive lines SD1 (Sb1Sb1 sb2sb2) and SD2 ( $s b 1 s b 1 S b 2 S b 2)$, and double dominant line DD ( $S b 1 S b 1 S b 2 S b 2)$. Except for spike type, agronomic traits of the four lines were similar in field appearances (Zhao et al., 2012).

All wheat lines were planted in Agronomy Experiment Station in Shandong Agricultural University from 2012 to 2013 growing season. The experiment plot was $10 \mathrm{~m}^{2}$ in three replicates by randomized block design. The wheat plants were thinly sowed at $6 \mathrm{~cm}$ plant spacing and $22 \mathrm{~cm}$ row spacing on October 8, 2012. Cultivation management was similar with common practice at local place.

Sowed wheat lines turned green at mid February in 2013. The young shoots were tripped out and observed under microscopy to determine the development of the shoot apexes. Experimental materials for hormones contents determination and expression analysis of hormone related gene were sampled once ten days for four times from the end of two ridge stage (February 21) and to pistil and stamen differentiation stage (March 2). The sampling times were corresponding with the end of two ridge stage, glume formation (in normal spike line) or branched rachis formation (in branched spike lines) stage, floret differentiation stage and pistil and stamen differentiation stage.

The whole seedlings were dug out and ice bathed, and young shoots, young leaves and tillering nodes were separated at low indoor light. Samples were quickly frozen in liquid nitrogen and stored at $-75^{\circ} \mathrm{C}$ for hormone determination and gene expression analysis. Young shoots were the remains removing all leaves above tillering note and they included the young spike (or shoot apex). Young leaves were the innermost leaf closed to the young shoot, and tillering nodes were the remaining part removing all roots and shoots.

\subsection{Extraction and Determination of Endogenous Hormones}

The experimental material $(0.3 \mathrm{~g})$ was used to measure the contents of the endogenous levels of IAA, ABA, GA and ZR. The immunoenzymatic method of analysis, as described by Li and Meng (Li et al., 1996), was used with some modifications. Materials were ice bathed under weak light and ground to homogenate in cold $80 \%$ methanol containing butylhydroxytoluene $(1 \mathrm{mM})$ as an antioxidant. After $4{ }^{\circ} \mathrm{C}$ overnight, the homogenate liquid was centrifuged for $15 \mathrm{~min}$ at $10,000 \mathrm{~g}$ (Avanti 30 centrifuge, Beckman), and The residue was washed and extracted with $2 \mathrm{ml}$ of cold methanol for another $12 \mathrm{~h}$, and centrifuged under the same conditions. The supernatants were combined and were filtrated in Sep-Pak C18 column twice so that the dilution curve was parallel to the curve of the standards. Elutes were vacuum-dried with a rotary evaporator at $37{ }^{\circ} \mathrm{C}$ to remove 
methanol. The residue was soluble again in a buffer containing $0.05 \mathrm{mM}$ Tris, $1 \mathrm{mM} \mathrm{MgCl} 2,150 \mathrm{mM} \mathrm{NaCl}, 0.1$ $\%$ gelatin, and $0.1 \%$ Tween 20 , and hormone extract were obtained. Contents of IAA, ABA, GA3 and ZR were determinate by enzyme linked immunosorbent assay (ELISA) according to the guide of testing set. The contents were determinate by SpectraMax Plus microplate and each sample was measured 3 times (Xie et al., 2003). ELISA Kit was purchased from China Agricultural University.

\subsection{RNA Extraction and Analysis of Real-Time PCR}

Total RNAs were extracted from experimental samples with TRIZOL (Invitrogen) according to the manufacturer's instructions. RNA yield and purity were checked by means of UV absorption spectra, whereas RNA integrity was determined by electrophoresis on agarose gel. DNA Removing and cDNA synthesis in total RNA used by TransScript TM One-Step gDNA Removal and cDNA Synthesis SuperMix Kit (Beijing Gold Biotechnology Co. Ltd.). Expressions of auxin amide hydrolase gene in wheat were analyzed. PCR Primers were designed by Primer Premiers v5.0 and synthesized by Shanghai Biotechnology Co., Ltd. The primer sequences used for real-time analysis are: P1: 5'-GCGTGGAATGGGAACATAAGAG-3', P2: 5'-TTTCTTGGCTCCACCACCAC-3'.

PCRs were carried out using TransStart Green qPCRSuperMix UDG Kit (Beijing Gold Biotechnology Co. Ltd.). Real-time RT-PCR was performed in a reaction mixture, final volume $10 \mu \mathrm{L}: 5 \mu \mathrm{l} 2 \times$ Trans Start Green qPCR Super Mix, $0.2 \mu 1$ 50×Passive Reference Dye (II), $0.2 \mu 1$ Primer P1 $\left(10 \mu \mathrm{mol} \mathrm{L}^{-1}\right), 0.2 \mu \mathrm{l}$ P2 $\left(10 \mu \mathrm{mol} \mathrm{L}{ }^{-1}\right), 0.5 \mu \mathrm{g}$ template, adding $\mathrm{ddH}_{2} \mathrm{O}$ to $10 \mu$. The reaction was taking place in aster cycler epgradient realple $\mathrm{x} 4$ (eppendorf). The reaction conditions were as follows: $95^{\circ} \mathrm{C}$ denaturing $120 \mathrm{~s}$; denaturation $5 \mathrm{~S}$ at $94{ }^{\circ} \mathrm{C}$, annealing at $60{ }^{\circ} \mathrm{C}$ for $25 \mathrm{~s}$, reading the fluorescence values, 40 cycles. Wheat $18 \mathrm{~S}$ rRNA was the internal standard, and each test repeated 3 times. After reaction melting curve was drawn at temperature from $60{ }^{\circ} \mathrm{C}$ to $95^{\circ} \mathrm{C}$. When curve was a single peak, the amplified product was single, and that is there was no nonspecific amplification. The obtained CT values were analyzed by averaging three independently calculated normalized expression values for each sample. PCR products were sequenced to ensure amplification products for the purpose of gene fragment. Expression values are given as the mean of the normalized expression values of the triplicates, calculated according to $2^{-\Delta \Delta \mathrm{CT}}$ method (Livak et al., 2001).

\subsection{Replication and Statistical Analysis}

Each experiment was carried out at least three times at different times. The data was analyzed by a one-way analysis of variance (ANOVA) and the means were separated using Duncan's multiple-range test (IBM SPSS Statistics Version 21). The level of significance in all comparisons was $p<0.05$.

\section{Results}

\subsection{Early Spike Developments of the Four Wheat NILs}

Survey on early development of young spike (shoot apex) indicated that there were slightly phenological differences existed among branched spike line and normal spike lines on inflorescence development progress. The period between the end of two ridges stage and the pistil and stamen differentiation stage is critical for the formation and elongation of branched rachis in branched spike wheat. The shoot apexes developed consistently in the three normal spike lines (DD, SD1 and SD2). The two ridges stage ended at about February 23, in the spring of 2012. The lines entered the glume differentiation stage and the stage lasted approximately 13 days. Afterwards, the floret differentiation stage and stamen and pistil differentiation stage lasted about 11 days and 6 days respectively. The normal spike lines entered anther connective stage at about March 23. There were about 30 days from the end of two ridges stage to pistil and stamen differentiation stage in the three normal spike lines.

Before the two ridges stage, the shoot apex in branched spike wheat line DR developed similarly with those in normal spike lines. All the shoot apexes went through the primary stage, the elongation stage, and the single and two ridges stages. At the end of two ridges stage (around February 23), the glume primordium in DR initiated slowly, and it seemed not to enter immediately the glume differentiation stage. At this time, new projection initiated at the position of spikelet primordium and extended as branched rachis, and afterwards, spikelet primordia formed in branched rachis. With the extension of branched rachis, floret primordium in branched rachis appeared and developed in accordance with normal developmental sequences in wheat spike, which underwent glume differentiation, floret formation and pistil and stamen differentiation. Branched spike line entered the glume differentiation at February 28, and it was 5 days later compared with the normal spike lines. Branched spike line entered anther connective stage at about March 25, and it was 2 days later compared with the normal spike lines. There were about 32 days from the end of two ridges stage to pistil and stamen differentiation stage in branched spike line, and that is 2 days longer than that in normal spike lines. 


\subsection{Dynamic Changes of the GA Contents}

The GA content in branched spike line had no obvious differences from those in normal spike lines. GA contents changed consistently in different tissues in all the four NILs, and showed increasing trends in different degrees in respective tissues (Figure 1). In young shoots, the GA contents in all the four NILs increased slowly. The GA contents at $10 \mathrm{~d}$ increased by $-3.1-13.2 \%$ than those at $0 \mathrm{~d}$ in their respective NILs, and the sequence of percentage increase in these NILs was SD1 $>$ SD2 $>$ DR $>$ DD. The GA contents at 20d increased by $11.0-30.5 \%$ than those at $0 \mathrm{~d}$ in their respective NILs, and the sequence of percentage increase was SD1 $>$ SD2 $>$ DR $>$ DD. The GA contents at $30 \mathrm{~d}$ increased by $18.1 \%-70.1 \%$ than those at $0 \mathrm{~d}$ in their respective lines, and the sequence of percentage increase was SD1 $>\mathrm{SD} 2>\mathrm{DD}>\mathrm{DR}$. In young leaves, GA contents increased slowly from $0 \mathrm{~d}$ to 10 $\mathrm{d}$ and $20 \mathrm{~d}$ in all the four NILs, but increased drastically from $20 \mathrm{~d}$ to $30 \mathrm{~d}$. The GA contents at $20 \mathrm{~d}$ increased by $11.0-89.2 \%$ than those at $0 \mathrm{~d}$ in their respective lines, and the sequences of percentage increase was SD1 $>$ SD2 $>$ DR $>$ DD. However, the GA contents at 30d increased by 47.3-108.7\% than those at $20 \mathrm{~d}$ in their respective lines, and the increase sequence was DR $>$ SD1 $>$ SD2 $>$ DD. Increase trends in tillering node in the four NILs appeared similar and the GA content in branched spike line DR was significantly lower than those in normal spike lines in all four development stages. The GA contents in DR were $62.5,74.3$ and $126.9 \mathrm{pmol} / \mathrm{g} \mathrm{FW}$ at $10 \mathrm{~d}$, $20 \mathrm{~d}$ and $30 \mathrm{~d}$, respectively.

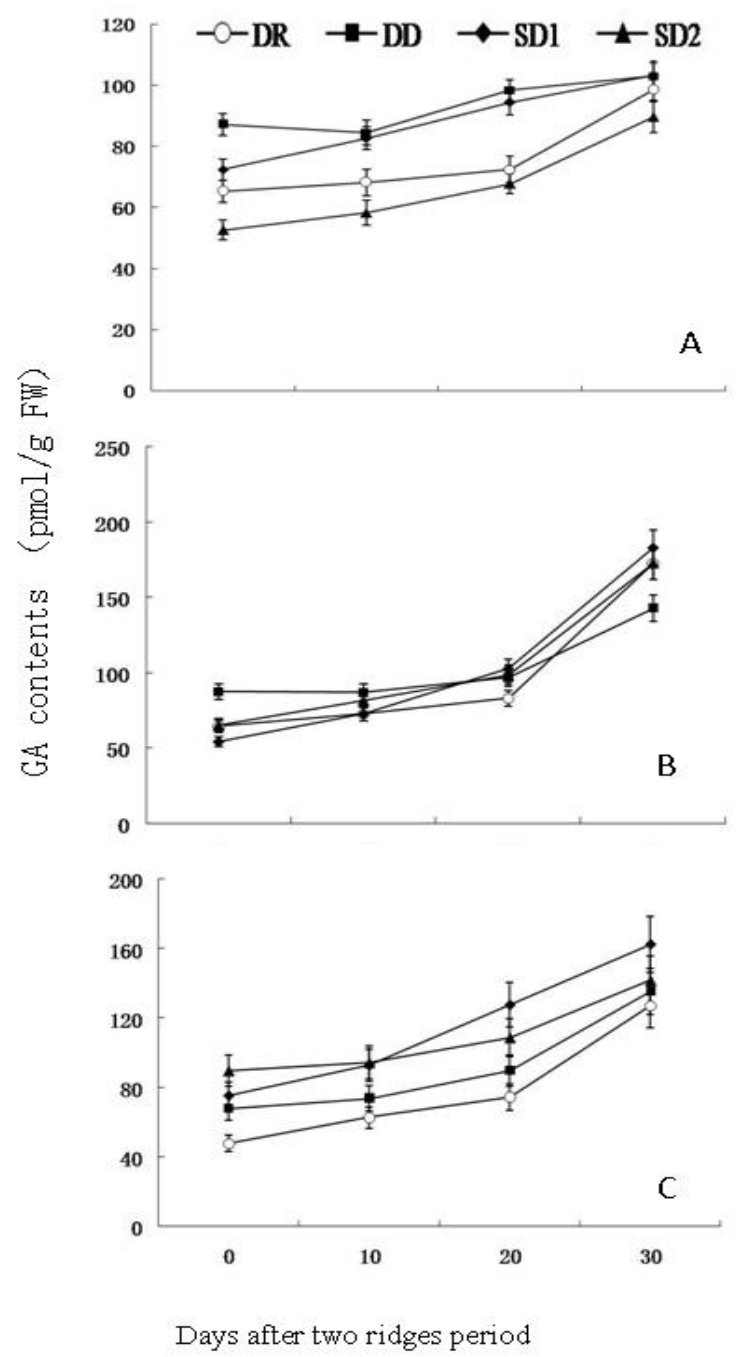

Figure 1. Dynamic changes of GA contents in different plant tissues (The upper, middle and lower charts were young shoots, young leaves and tillering nodes, respectively) in the four NILs after two ridges stage. Data are the means of three independent experiments $\pm \mathrm{SD}$ 


\subsection{Dynamic Changes of IAA Contents}

IAA contents in all the four NILs increased as young spike developed (Figure 2). The increases ranges in young shoot and young leaves showed distinctly different between the branched spike line and the normal spike lines. In young shoot, IAA contents at $10 \mathrm{~d}, 20 \mathrm{~d}$ or $30 \mathrm{~d}$ were not significantly different among the three normal spike lines, but the IAA contents in branched DR were significantly higher than those in normal spike lines. The highest IAA content in DR appeared at $20 \mathrm{~d}$, and it reached 3.6 times higher than the average IAA contents in the three normal lines. The IAA content gap between DR and the normal spike lines in young leaves were lower than that in young shoots, but the IAA content in DR was also significantly higher than the average IAA contents in the normal spike lines. The IAA contents in DR at $20 \mathrm{~d}$ reached 1.35 times higher than the average IAA content in normal spike lines. No obvious difference was found in IAA contents in tillering node between branched spike and normal spike lines. The IAA contents at $30 \mathrm{~d}$ increased by $62.4-112.0 \%$ than those in their respective lines at $0 \mathrm{~d}$. The sequences of percentage increase were SD2 $>\mathrm{DD}>\mathrm{SD} 1>\mathrm{DR}, \mathrm{SD} 2>\mathrm{SD} 1>\mathrm{DR}>\mathrm{DD}$ and SD2 $>\mathrm{DR}$ $>$ DD $>$ SD at $10 \mathrm{~d}, 20 \mathrm{~d}$ and $30 \mathrm{~d}$, respectively.

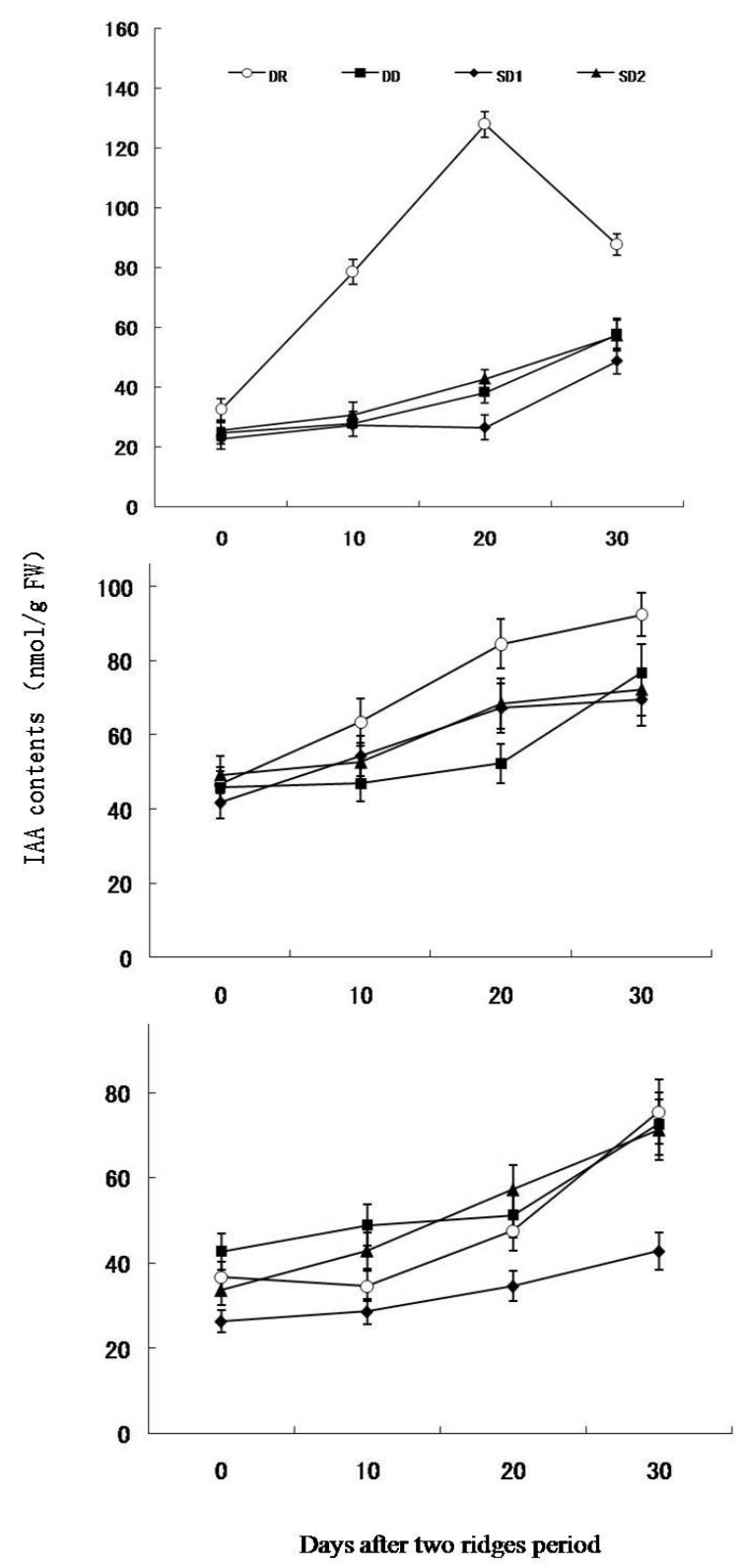

Figure 2. Dynamic changes of IAA contents in different plant tissues (The upper, middle and lower charts were young shoots, young leaves and tillering nodes, respectively) in the four NILs after two ridges stage. Data are the means of three independent experiments $\pm \mathrm{SD}$ 


\subsection{Dynamic Changes of ZR Contents}

The changes of ZR contents in the four NILs exhibited a complicated pattern, depending on tissues and growth stages. In the same tissue, the ZR change trends displayed similarly in the four NILs, and there were no distinctive differences between branched spike line and normal spike lines (Figure 3). In young shoots, the ZR contents increased slowly and reached the highest value at $30 \mathrm{~d}$. The ZR contents at $30 \mathrm{~d}$ in the four NILs increased by $133.3-395.6 \%$ than their respective ZR contents at $0 \mathrm{~d}$, and the sequence of percentage increase was $\mathrm{SD} 2>\mathrm{DR}>\mathrm{DD}>\mathrm{SD}$. In young leaves, except that DR had the highest ZR content at $30 \mathrm{~d}$, all other lines had the highest ZR value at $20 \mathrm{~d}$. The ZR contents in normal spike line SD1 was higher than those in other three lines at the four experimental times. In tillering node, the change trend of ZR content in branched spike line was similar with those in normal spike lines. ZR contents in all lines increased dramatically at later development. The ZR contents at $20 \mathrm{~d}$ increased $14.7-140.2 \%$ than those at $0 \mathrm{~d}$ and the $\mathrm{ZR}$ contents at $30 \mathrm{~d}$ increased $88.1-158.1 \%$ than those at $0 \mathrm{~d}$.

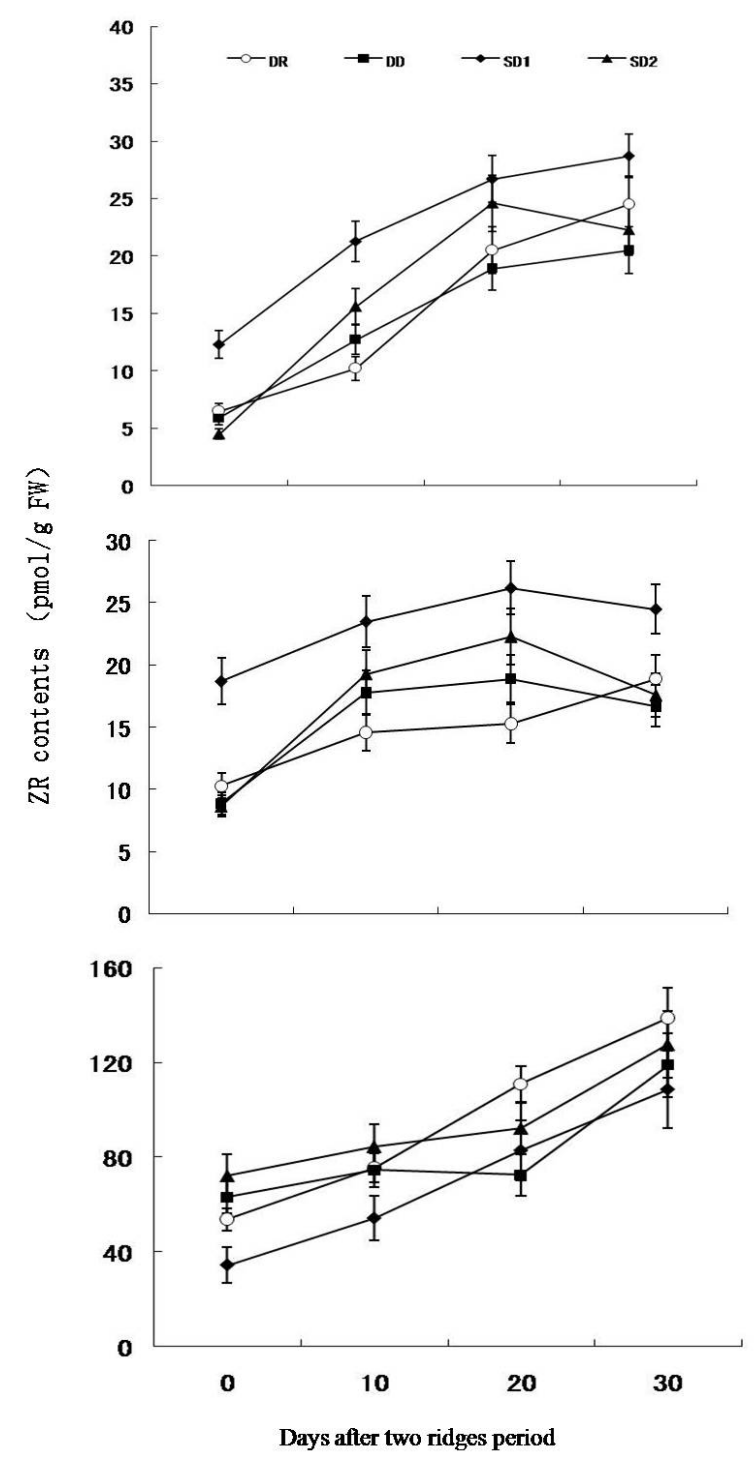

Figure 3. Dynamic changes of ZR contents in different plant tissues (The upper, middle and lower charts were young shoots, young leaves and tillering nodes, respectively) in the four NILs after two ridges stage. Data are the means of three independent experiments $\pm \mathrm{SD}$

\subsection{Dynamic Changes of ABA Contents}

ABA changes in the four NILs had their owe characters compared with the three other phytohormones. Although 
ABA contents in the three tissues increased from $0 \mathrm{~d}$ to $30 \mathrm{~d}$, the increase range of ABA contents was much lower than those of other three hormones (Figure 4). The ABA contents in young shoot displayed two peaks in the four NILs. The ABA contents at $10 \mathrm{~d}$ and $30 \mathrm{~d}$ was higher than those at $0 \mathrm{~d}$ and $20 \mathrm{~d}$ in their respetive lines. The ABA contents at $10 \mathrm{~d}$ increased $14.5-89.4 \%$ than those in their respective lines at $10 \mathrm{~d}$, and the sequence of percentage increase was SD2 $>$ DD $>$ DR $>$ SD1. The ABA contents at $30 \mathrm{~d}$ increased $8.1-47.8 \%$ than those at 20 $\mathrm{d}$, and the increase was DD $>$ SD2 $>$ DR $>$ SD1. In young leaves, the ABA contents in the four NILs showed similar trends in the NILs, and the increase range varied little as the spike developed. The ABA contents at $30 \mathrm{~d}$ increased by $5.8-88.9 \%$ than those in their respective lines at $0 \mathrm{~d}$, and the sequence of percentage increase was $\mathrm{DR}>\mathrm{SD} 2>\mathrm{DD}>\mathrm{SD} 1$. In tillering node, the ABA contents in normal spike line SD1 had different characters with the other three lines. The highest value of ABA content in SD1 was at $20 \mathrm{~d}$ and those in the other three lines were at $30 \mathrm{~d}$. The ABA contents in the SD1 at $20 \mathrm{~d}$ increased by $67.4 \%$ than those at $0 \mathrm{~d}$ and the ABA contents in the other three lines at $30 \mathrm{~d}$ increased by $30.2-140.7 \%$ than their respective lines at $0 \mathrm{~d}$.

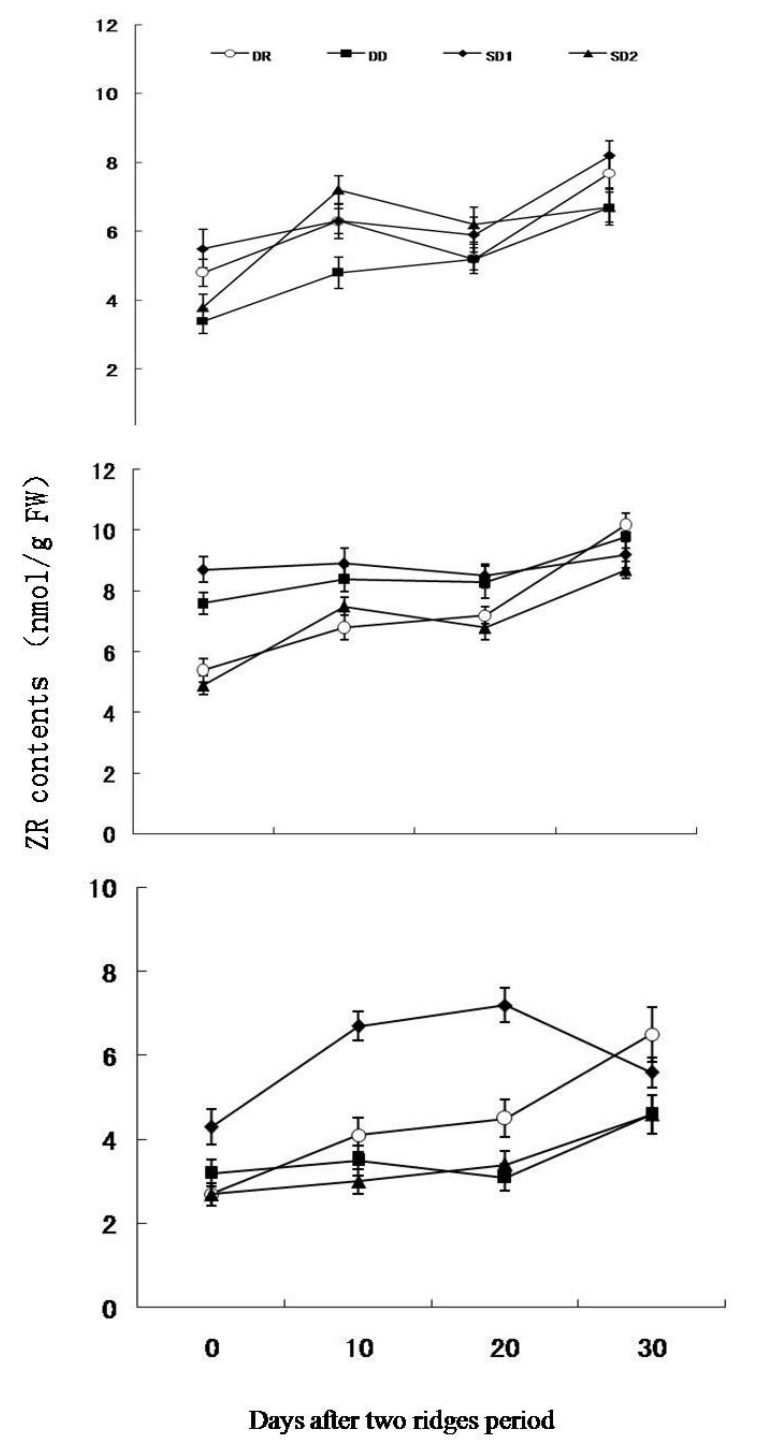

Figure 4. Dynamic changes of ABA contents in different plant tissues (The upper, middle and lower charts were young shoots, young leaves and tillering nodes, respectively) in the four NILs after two ridges stage. Data are the means of three independent experiments $\pm \mathrm{SD}$

\subsection{Dynamic Changes of the Expression of Auxin Synthesis Related Gene TaIAR3 in the Four NILs}

The results of hormone content changes indicated the auxin contents might be related with the differences of spike morphology between branched spike wheat line and normal spike lines. Expression of auxin synthesis gene 
TaIAR3 was measured by real time quantitative PCR. The results showed that the expressions of TaIAR3 in branched spike line had distinct differences with the normal spike lines (Figure 5) in young shoots and young leaves, and the expression of TaIAR3 displayed similar trends with the IAA contents changes in branched spike line or normal spike lines respectively. In young shoot, the expression of TaIAR3 in branched spike line had distinct increased trends, which was significantly different with those normal spike lines. The expression levels of TaIAR 3 in branched spike line at $10 \mathrm{~d}$ and $20 \mathrm{~d}$ were much higher than those in normal spike lines, and were more than 1.99, 1.79, and 1.09 times higher than the average level of TaIAR3 expressions in the three normal spike lines at $10 \mathrm{~d}, 20 \mathrm{~d}$ and $30 \mathrm{~d}$, respectively. In young leaves, the expression curves of the four NILs showed parallel as the spike development, but the expression of TaIAR3 in branched spike lines were much higher than those in other three normal spike lines. In tillering node, the expression of TaIAR3 in the four NILs increased as developed, but the branched spike line did not show distinctly different characters from normal lines.
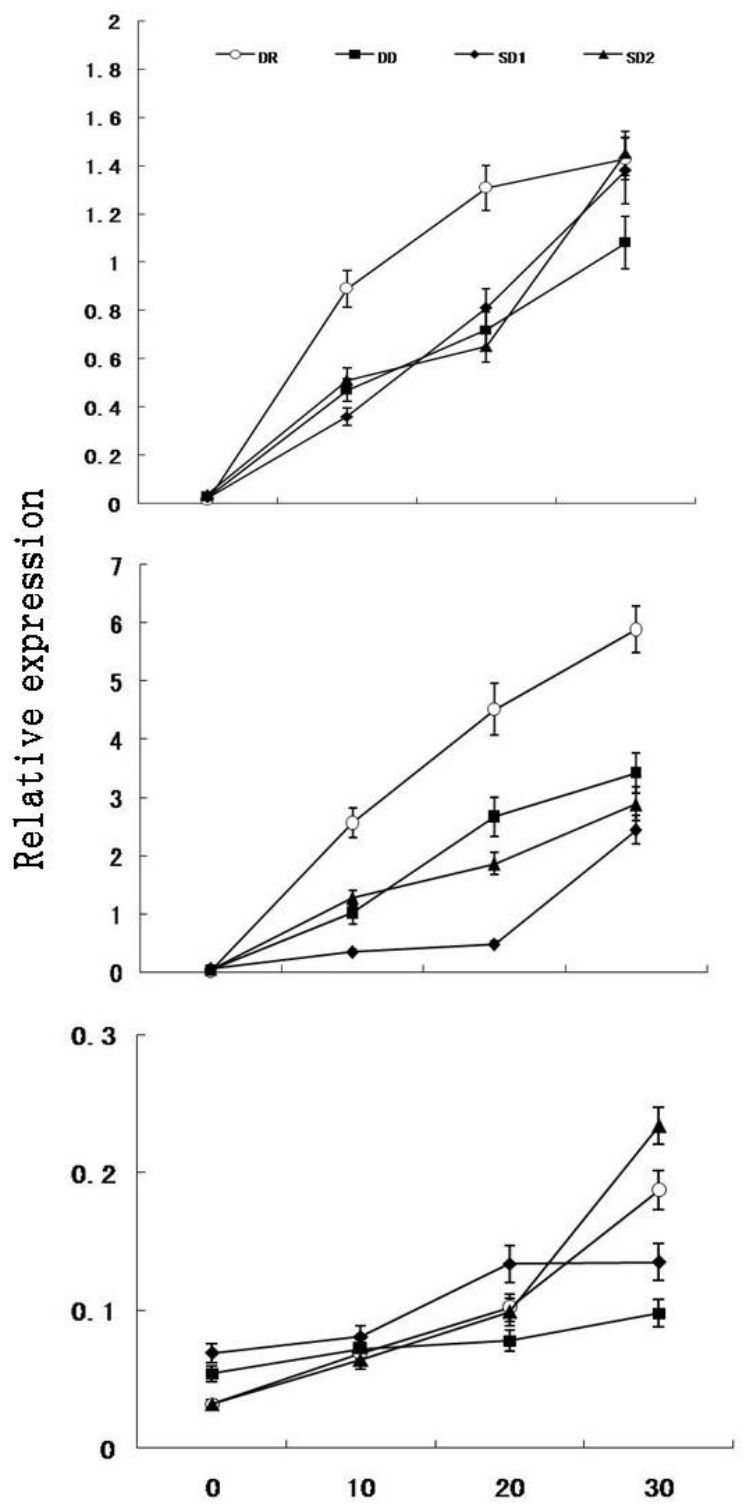

\section{Days after two ridges period}

Figure 5. Expression patterns of TaIAR3, a IAA synthesis related gene, in different plant tissues (The upper, middle and lower charts were young shoots, young leaves and tillering nodes, respectively) in the four NILs after two ridges stage. Data are the means of three independent experiments $\pm \mathrm{SD}$ 


\section{Discussion}

Our past research indicated that the periods from the end of two ridge stage to the pistil and stamen differentiation was the key period for occurrence and development for branched rachis (Zhao et al., 2013). This research indicated the branched spike line had distinctive auxin change patterns and much higher auxin contents than their countparts in normal spike lines in young shoot and leaves. Meanwhile, the expression of IAA synthesis-related gene TaIAR 3 was also significantly higher than those in normal lines during this period. These manifested that the increase of auxin content and auxin synthesis gene expression might play a key role for the formation and extension of branched rachises in branched spike wheat.

Auxin plays a critical important role in regulating plant branching, including the underground root system and the aboveground shoot branching system. Auxin is involved in the formation and growth lateral root, which is root branching. IAA plays a positive role during the lateral root primordial formation and initial development stage of lateral root (Laskowski et al., 1995; Fukaki et al., 2009). Spraying exogenous auxin increased lateral root number, and inhibiting auxin transport could reduce the number of lateral root (Reed et al., 1998). It has been know for many years that auxin inhibits the activation of axillary buds, and hence shoot branching. Auxin has long been known to contribute to branching, although the mechanistic basis of its function remains somewhat ambiguous (Waldie et al., 2010). Auxin promotes apical dominacnce through a pathway whereby auxin derived from the main shoot apex inhibit the outgrowth of lower axillary buds. Most of the researches on effects of auxin on shoot branching focused on its molecular mechanisms in auxin biosynthesis, metabolism, polar transport and signal transduction. AXR1 (Auxin Resistant 1) responses to exogenous auxin and influences shoot branching by regulating auxin signal transduction (del Pozo, 1999; Stirnberg et al., 1999; Gray et al., 2001). In Arabidopsis max mutant (more axillary branching), auxin signaling system regulates plant branching (Parry et al., 2006) and increasing auxin transport could promote branching (Bennett et al., 2006). This kind of branching mutant with related auxin levels have been found in many plants, including Arabidoposis thaliana, Pisum sativum, Petunia and rice (Ward et al., 2004; McSteen et al., 2005). Our research indicted that auxin might involved in the formation and development of branched rachis in inflorescence of branched spike wheat.

In plants, the plant hormone indole-3-acetic acid (IAA) is found both free and conjugated to a variety of amino acids, peptides, and carbohydrates. Indoleacetamide hydrolase catalyzes the formation of indole acetic acid from indole acetamide, and leads directly to the increase of auxin level in plant tissues (Staswick et al., 2005). TaIAR3, an ortholog for the Arabidopsis IAR3 auxin amidohydrolase gene isolated from wheat is able to cleave conjugates of auxin molecules with longer side chains (LeClere et al., 2002; Campanella et al., 2003). In addition, the TaIAR 3 mRNA shows a different spatial and temporal regulation compared to IAR3 from Arabidopsis (Davies et al., 1999; Rampey et al., 2003), suggesting that TaIAR3 enzymes may be employed in different developmental pathways in wheat. Temporal expression studies of TaIAR3 indicate that the transcript is initially expressed at day 1 after germination and then expression decreases through days 2, 5, 10, 15, and 20. Spatial expression studies found similar levels of expression throughout all wheat tissues examined (Campanella et al., 2004). Our study results showed that the transcription level of TaIAR3 in branched spike line increased much higher than those in normal spike lines in young shoot and young leaves after the two ridges stage. It might involve in the development process of young spikes in wheat.

It is worth pointing out that auxin might not be the only factors influencing the branched spike formation in wheat. Firstly, many other hormones might involve in the branched rachis formation in plants. In shoot branching, IAA and CTK regulate branching development coordinately. IAA inhibits the branching development and CTK improves the growth of branching (Ongaro et al., 2008). Strigolactone regulate the level of CTK content by feedback regulation and then influence the development of branching in all rms mutants of Pisum sativum and max mutants of Aribidopsis thaliana (Foo et al., 2007). Secondly, early research indicated that spraying exogenous hormones on normal spike wheat during early development periods could influence spike morphology, including producing many adventurous spike branching. However, these adventurous branching in main rachis were generally irregular, which was distinctly different from that in branched spike wheat (Sharman, 1978; Huang et al., 1990).

\section{Conclusion}

Compared with normal spike lines, the change patterns of IAA contents in branched spike line showed distinctly different during the key period of branched rachis formation and elongation. As the young spike developed, the IAA contents in branched spike wheat were much higher than those in normal spike lines, and the contents of GA, ZR and ABA displayed similar change patterns between the two types of wheat lines with different spikes. Meanwhile, the relative expression of TaIAR3 in branched spike wheat line was also significantly higher than 
those those in normal spike lines, and the expressions in the four NILs displayed similar change trends with IAA contents in their respective lines. The differences on IAA contents and expressions of auxin synthesis related gene might be responsible for spike morphologies and higher IAA content and higher expression level of TaIAR3 might promote the formation and growth of branched rachis in branched spike wheat.

\section{Acknowledgements}

This research is supported by Key Program for Natural Sciences Fund in Shandong Province (ZR2012CZ001), Wheat Breeding and Demonstration for high and stable yield, high quality in Henan Grain Core Area supported by Ministry of science and technology in China (2011BAD07B01) and by Special Program from Ministry of science and technology in China (2011ZX08002-003). Many thanks to the graduated and in-reading students from Agronomy College, Shandong Agricultural University taking part in much work in the fields. Great thanks also to wheat breeder Professor Shao Zixing in Agricultural Science College of Taian, who kindly provided the original wheat materials in this research.

\section{References}

Bennett, T., \& Leyser, O. (2006). Something on the side: Axillary meristems and plant development. Plant. Mol. Bio., 60, 843-854. http://dx.doi.org/10.1007/s11103-005-2763-4

Beveridge, C. A. (2006). Axillary bud outgrowth: sending a message. Curr. Opin. Plant Biol., 9, 35-40. http://dx.doi.org/10.1016/j.pbi.2005.11

Brewer, P. B., Dun, E. A., Ferguson, B. J., Rameau, C., \& Beveridge, C. A. (2009). Strigolactone acts downstream of auxin to regulate bud outgrowth in pea and Arabidopsis. Plant Physiol., 150, 482-493. http://dx.doi.org/10.1104/pp.108.134783

Campanella, J. J., Bakllamaja, V., Restieri, T., Vomacka, M., Herron, J., Patterson, M., \& Shahtaheri, S. (2003). Isolation of an ILR1 auxin conjugate hydrolase homolog from Arabidopsis suecica. Plant Growth Regul., 39, 175-181. http://dx.doi.org/10.1023/A:1022528318188

Campanella, J. J., Olajide, A. F., Magnus, V., \& Ludwig-Müller, J. (2004). A Novel Auxin Conjugate Hydrolase from Wheat with Substrate Specificity for Longer Side-Chain Auxin Amide Conjugates. Plant Physiol., 135(4), 2230-2240. http://dx.doi.org/10.1104/pp.104.043398

Cohen, J. D., Slovin, J. P., \& Hendrickson, A. M. (2003). Two genetically discrete pathways convert tryptophan to auxin: more redundancy in auxin biosynthesis. Trends Plant Sci., 8, 197-199. http://dx.doi.org/10.1016/s1360-1385(03)00058-x

Davies, R. T., Goetz, D. H., Lasswell, J., Anderson, M. N., \& Bartel, B. (1999). IAR3 encodes an auxin conjugate hydrolase from Arabidopsis. Plant Cell, 11, 365-376. http://dx.doi.org/10.1105/tpc.11.3.365

del Pozo, J. C., \& Estelle, M. (1999). The Arabidopsis cullin AtCUL1 is modified by the ubiquitinrelated protein RUB1. Proc. Natl. Acad. Sci. USA, 96, 15342-15347. http://dx.doi.org/10.1073/pnas.96.26.15342

Dencic, S. (1988). Genetic analysis of different structures of sink capacity in wheat. Proc. 7th Intern (pp. 499-502). Wheat Genet. Symp. Cambridge, UK.

Domagalska, M. A., \& Leyser, O. (2011). Signal integration in the control of shoot branching. Nat. Rev. Mol. Cell. Biol., 12, 211-221. http://dx.doi.org/10.1038/nrm3088

Emery, R. J. N., Longnecker, N. E., \& Atkins, C. A. (1998). Branch development in Lupinus angustifolius L. II. Relationship with endogenous ABA, IAA and cytokinins in axillary and main stem buds. J. Exp. Bot., 49, 555-562. http://dx.doi.org/10.1093/jxb/49.320.555

Foo, E., Buillier, E., Goussot, M., Foucher, F., Rameau, C., \& Beveridge, C. A. (2005). The branching gene RAMOSUS1 mediates interactions among two novel signals and auxin in pea. Plant Cell, 17, 464-474. http://dx.doi.org/10.1105/tpc.104.026716

Foo, E., Morris, S. E, Parmenter, K., Young, N., Wang, H., Jones, A., ... Beveridge, C. A. (2007). Feedback regulation of xylem cytokinin content is conserved in pea and Arabidopsis. Plant Physiol., 143, 1418-1428. http://dx.doi.org/10.1104/pp.106.093708

Fukaki, H., \& Tasaka, M. (2009). Hormone interactions during lateral root formation. Plant. Mol. Biol., 69, 437-449. http://dx.doi.org/10.1007/s11103-008-9393-6

Gomez-Roldan, V., Fermas, S., Brewer, P. B., Puech-Pages, V., Dun, E. A., \& Pillot, J. P. (2008). Strigolactone inhibition of shoot branching. Nature, 455, 189-194. http://dx.doi.org/10.1038/nature07271 
Gray, W. M., Kepinski, S., Rouse, D., Leyser, O., \& Estelle, M. (2001). Auxin regulates SCFTIR1-dependent degradation of AUX/IAA proteins. Nature, 414, 271-276. http://dx.doi.org/10.1038/35104500

Hooijdonk, B. M., Woolley, D. J., Warrington, I. J., \& Tustin, D. S. (2011). Initial alteration of shoot architecture by dwarfing apple rootstocks involves shoot/root/shoot signalling between auxins, gibberellins and cytokinins. Acta. Horti., 903, 857-863.

Huang, G., \& Yan, J. (1990). Genetics studies of branched spike in common wheat. J. Southwestern Agricul., 3(2), 7-11.

Huang, G., \& Yen, C. (1988). Studies on the developmental genetics of multiple spikelet per spike in wheat. Proc. 7th Intern. (pp. 527-532). Wheat Genet Symp, Cambridge, UK.

Koric, S. (1975). Genetic basis for high spike productivity. Proceedings of the 2nd Intern Winter wheat Conference, Zagreb, Yugoslavia (pp.188-144). U.S. Department of Agriculture.

Koric, S. (1980). Study of branched gene complex of Triticum aestivum ssp. vulgare and its significance for wheat breeding. J. Sci. Agric. Res. Zagreb. Yugoslavia., 142, 271-282.

Laskowski, M. J., Williams, M. E., Nusbaum, H. C., \& Sussex, I. M. (1995). Formation of lateral root meristems is a two-stage process. Development, 121, 3303-3310.

LeClere, S., Tellez, R., Rampey, R. A., Matsuda, S. P. T., \& Bartel, B. (2002). Characterization of a family of IAA-amino acid conjugate hydrolases from Arabidopsis. J. Biol. Chem., 277, 20446-20452. http://dx.doi.org/10.1074/jbc.M111955200

Leyser, O. (2003). Regulation of shoot branching by auxin. Trends. Plant. Sci., 8, 541-545. http://dx.doi.org/10.1002/9780470015902.a0020122

Li, X. J., \& Meng, F. J. (1996). Study on the photoperiodic-induced flowering in soybean: changes of plant hormones and assimilates of the first leaves. J. China Agric. Univ., 1, 35-39.

Livak, K. J., \& Schmittgen, T. D. (2001). Analysis of relative gene expression data using real-time quantitative PCR and the $2^{-\Delta \Delta C T}$ method. Methods, 25(4), 402-408. http://dx.doi.org/10.1006/ meth.2001.1262

McSteen, P., \& Leyser, O. (2005). Shoot branching. Annu. Rev. Plant. Biol., 56, $353-374$. http://dx.doi.org/10.1146/annurev.arplant.56.032604.144122

Ongaro, V., \& Leyser, O. (2008). Hormonal control of shoot branching. J. Exp. Bot., 59, 67-74. http://dx.doi.org/10.1093/jxb/erm134

Parry, G., Ward, S., Cernac, A., Dharmasiri, S., \& Estelle, M. (2006). The Arabidopsis SUPPRESSOR OF AUXIN RESISTANCE proteins are nucleoporins with an important role in hormone signaling and development. Plant Cell, 18, 1590-1603. http://dx.doi.org/10.1105/tpc.106.041566

Peanell, A. L., \& Halloran, G. M. (1983). Inheritance of supernumerary spikelet development in wheat. Euphytca, 32, 767-776. http://dx.doi.org/10.1007/BF00042157

Rampey, R. A., LeClere, S., \& Bartel, B. (2003). The roles of Arabidopsis IAA conjugate hydrolases in auxin homeostasis. Proceedings of the American Society of Plant Biologists Conference. Honolulu, HI, USA. Retrieved from http://abstracts.aspb.org/pb2003/public/P46/0446.html

Reed. R. C., Brady, S. R., \& Muday, G. K. (1998). Inhibition of auxin movement from the shoot into the root inhibits lateral root development in Arabidopsis. Plant. Physio., 118, 1369-1378. http://dx.doi.org/10.1104/pp.118.4.1369

Sharman, B. C. (1978). Morphogenesis of 2,4-D induced abnormalities of bread wheat (Triticum aestivuum L.). Anna. Bot., 42, 145-153.

Staswick, P., Serban, B., Rowe, M., Tiryaki, I., Maldonado, M. T., Maldonado, M. C., \& Suza, W. (2005). Characterization of an Arabidopsis enzyme family that conjugates amino acids to indole-3-acetic acid. Plant Cell, 17, 616-627. http://dx.doi.org/10.1105/tpc.104.026690

Stirnberg, P., Chatfield, S. P., \& Leyser, H. M. (1999). AXR1 acts after lateral bud formation to inhibit lateral bud growth in Arabidopsis. Plant Physiol., 121, 839-847. http://dx.doi.org/10.1104/pp.121.3.839

Sun, D. F., Zhu, X. D., Wan, Z. B., \& Cai, J. (2000). The stability and expression in F1 generation of supernumerary spikelets in bread wheat. J. Huazhong Agric. Univ., 19, 213-218.

Tanaka. M., Takei, K., Kojima, M., Sakakibara, H., \& Mori, H. (2006). Auxin controls local cytokinin 
biosynthesis in the nodal stem in apical dominance. Plant J., 45, 1028-1036. http://dx.doi.org/10.1111/j.1365-313X.2006.02656.x

Umehara, M., Hanada, A., Yoshida, S., Akiyama, K., Arite, T., \& Takeda-Kamiya, N. (2008). Inhibition of shoot branching by new terpenoid plant hormones. Nature, 455, 195-200. http://dx.doi.org/10.1038/nature07272

Waldie, T., Hayward, A., \& Beveridge, C. A. (2010). Axillary bud outgrowth in herbaceous shoots: how do strigolactones fit into the picture? Plant. Mol. Biol., $73, \quad 27-36$. http://dx.doi.org/10.1007/s11103-010-9599-2

Ward, S. P., \& Leyser, O. (2004). Shoot branching. Curr. Opin. Plant. Biol., 7, 73-78. http://dx.doi.org/10.1016/j.pbi.2003.10.002

Xie, Z., Jiang, D., Cao, W. X., Dai, T. B., \& Jing, Q. (2003). Relationships of endogenous plant hormones to accumulation of grain protein and starch in winter wheat under different post-anthesis soil water statuses. Plant Growth. Regul., 41, 117-127. http://dx.doi.org/10.1023/A\%3A1027371906349

Zhang, W. D., Li, A. F., Tian, J. C., \& Zhao, L. F. (2012). Development of Near Isogenic Lines of Wheat Carrying Different Spike Branching Genes and Their Agronomic and Spike Characters. J. Agricul. Sci., 4(8), 215-221. http://dx.doi.org/10.5539/jas.v4n8p215

Zhao, L. F., Zhang, W. D., Gao, Q. R., Li, A. F., \& Tian, J. C. (2012). Characters of Rachis and Grain within Different Spike Parts in Spike Hetero Branching Wheat (Triticum aestivum L.). J. Agricul. Sci., 4(12), 106-115. http://dx.doi.org/10.5539/jas.v4n12p106

Zhao, L. F., Zhang, W. D., Tian, J. C., Gao, Q. R., \& Wang, Z. D. (2013). Research on Development of Growing Tip and Its Phonological Characters in Spike-Branched Wheat Utilizing Two Near-isogenic lines. Shandong Agricul. Sci., 45(3), 21-24, 27. http://dx.doi.org/10.3969/j.issn.1001-4942.2013.03.006

\section{Copyrights}

Copyright for this article is retained by the author(s), with first publication rights granted to the journal.

This is an open-access article distributed under the terms and conditions of the Creative Commons Attribution license (http://creativecommons.org/licenses/by/3.0/). 